\title{
DETERMINAÇÃO DA ABSORTÂNCIA PELO MÉTODO DE PADRÕES COMPARATIVOS
}

\author{
G. G. Nobre ${ }^{1 *}$, E. Bauer ${ }^{2}$ \\ *Autor de Contato: guilhermegnobre.eng@gmail.com \\ ${ }^{1}$ Departamento de Engenharia Civil e Ambiental, Programa de Pós-Graduação em Estruturas e Construção Civil, \\ Universidade de Brasília, Brasília, Brasil \\ ${ }^{2}$ Departamento de Engenharia Civil e Ambiental, Programa de Pós-Graduação em Estruturas e Construção Civil, \\ Universidade de Brasília, Brasília, Brasil
}

\begin{abstract}
RESUMO
A absortância é uma propriedade para realizar análises e simulações térmicas, pois permite a obtenção de resultados mais fidedignos. Com base nisto, este artigo objetiva a aplicação de uma metodologia de comparação, adaptado de Dornelles (2007b) para determinação dos valores aproximados da absortância. Com o auxílio de um banco de dados e do programa WUFI Pro 5.0 ${ }^{\circledR}$, são realizadas simulações na orientação norte, de quatro edifícios distintos, para análises da temperatura máxima e da amplitude térmica, como forma de exemplificar a utilização da absortância. Os resultados apresentados mostraram que a absortância tem grande influência nos pontos analisados e que a metodologia aplicada é uma alternativa para determinar valores aproximados de absortância para as simulações.
\end{abstract}

Palavras chave: Absortância; Simulação; Fluxo de calor; Temperatura; Amplitude térmica.

\section{RESUMEN}


La absorbancia es una propiedad para realizar análisis y simulaciones térmicas, ya que permite obtener resultados más fiables. Con base en esto, este artículo tiene como objetivo aplicar una metodología de comparación, adaptada de Dornelles (2007b) para determinar los valores aproximados de absortancia. Con la ayuda de una base de datos y el programa WUFI Pro $5.0 \AA$, se realizan simulaciones en la orientación norte, de cuatro edificios diferentes, para el análisis de la temperatura máxima y la amplitud térmica, como una forma de ejemplificar el uso de la absortancia. Los resultados presentados mostraron que la absortancia tiene una gran influencia en los puntos analizados y que la metodología aplicada es una alternativa para determinar valores de absortancia aproximados para las simulaciones.

Palabras llave: Absorbancia; Simulación; Flujo de calor; Temperatura; Rango térmico.

\begin{abstract}
Absorptance is a property to perform thermal analysis and simulations, as it allows obtaining more reliable results. Based on this, this article aims to apply a comparison methodology, adapted from Dornelles (2007b) to determine approximate absorptance values. With the help of a database and the WUFI Pro $5.0 \AA$ program, simulations are carried out in the north orientation, of four different buildings, for analysis of the maximum temperature and the thermal amplitude, as a way of exemplifying the use of absorptance. The presented results showed that the absorptance has a great influence on the analyzed points and that the applied methodology is an alternative to determine approximate absorptance values for the simulations.
\end{abstract}

Keywords: Absorptance; Simulation; Heat flux; Temperature; Thermal range.

\title{
1. INTRODUÇÃO
}

A radiação proveniente do Sol atinge a Terra na forma de ondas eletromagnéticas curtas, alcançando as edificações de três formas distintas (ZANONI, 2015). Essas são denominadas: radiação direta, difusa e refletida, onde a somatória destas denomina-se radiação total. A radiação direta é a que passa pela atmosfera e vai diretamente à superfície analisada, sem sofrer grandes alterações. Já a radiação difusa, ao passar pela atmosfera, sofre processos de difusão, reflexão e absorção, os quais dependem das nuvens e de partículas que compõem a atmosfera. A radiação refletida ao passar pela atmosfera, atinge outros corpos e reflete para a superfície da fachada (ZANONI, 2015).

Vale salientar que a principal fonte responsável pelo ganho térmico das edificações é a radiação solar, principalmente em regiões de clima quente (COELHO et. al., 2017). A radiação também se altera dependendo da orientação em que se encontra a edificação, onde no hemisfério norte as regiões críticas são a sul e oeste, já no hemisfério sul se altera para norte e oeste (SILVA, 2014; NASCIMENTO, 2016).

A absortância pode ser definida pela razão entre a taxa de radiação solar absorvida pela taxa de radiação total emitida sobre uma dada superfície (ABNT, 2005). A radiação total que incide sobre uma superfície pode ter três comportamentos distintos: pode ser absorvida (absortância), refletida (refletância) ou atravessa (transmitância), sendo que a soma desses três deve ser a unidade (RORIZ, 2008).

A radiação total (It) incidente sobre uma vedação opaca é dividida em duas partes distintas, sendo que uma é absorvida (It. $\alpha$ ) e outra é refletida (It. $\rho$ ), pois a transmitância é zero. A absortância tem relação direta com o acréscimo de temperatura superficial, ou seja, quanto maior a absortância, 
maior será a radiação absorvida e como consequência maior o incremento de temperatura na superfície (COELHO et. al., 2017).

As tonalidades claras possuem absortância menor, quando comparado com tonalidades escuras. Isso ocorre porque cores claras tem facilidade de refletir, enquanto cores escuras absorvem a radiação incidente (RORIZ, 2008). Por isso fachadas com valores de absortância menores, tendem a aquecer menos quando comparados a valores de absortância maiores.

A norma brasileira de desempenho (ABNT, 2013) expõe três valores de absortância, sendo divididos em cor clara $(\alpha=0,3)$, cor média $(\alpha=0,5)$ e cor escura $(\alpha=0,7)$. Tal classificação dificulta a análise do desempenho térmico em edificações. Chvatal (2014) correlacionou os resultados obtidos pelo procedimento de avaliação simplificada da NBR 15575 (ABNT, 2013) e pela simulação chegou à conclusão que os métodos produzem respostas distintas e que o procedimento de avaliação simplificada não é sensível à ação da transmitância e da absortância.

Com base no que é exposto, este trabalho tem como objetivo descrever uma metodologia fundamentada na avaliação comparativa adaptada de Dornelles (2007b), para determinar o valor aproximado da absortância das fachadas. Propõe-se então a aplicação dos valores de absortância na simulação higrotérmica do programa WUFI Pro $5.0 \AA$, analisando os valores de temperatura máxima e amplitude térmica de quatro edifícios localizados em Brasília - Brasil.

\section{MÉTODOS}

\subsection{Detalhando o método de estimativa da absortância}

A fim de definir o valor aproximado da absortância a ser usado, utiliza-se o trabalho de Dornelles (2007b) com algumas adaptações, que descreve cinco grupos de tonalidades com suas respectivas absortâncias. Os cinco grupos de tonalidades são conjuntos de 78 cores ao todo, das quais são descritas a absortância correspondente. Neste caso, separa-se todas as cores semelhantes à fachada em análise, de pelo menos quatro dos cinco grupos e exclui-se os valores extremos, optando por um dos valores intermediários. Vale ressaltar que não recomenda-se calcular o valor médio das absortâncias, e sim usar um valor estabelecido dentro dos grupos.

O método pode ser exemplificado com uma fachada hipotética, onde selecionam-se todas as cores similares nos cinco grupos presentes no trabalho de Dornelles (2007b) e retira-se os valores maiores e menores de absortância, até que reste apenas um valor intermediário. Vale ressaltar que Dornelles (2007b) traz uma tabela com as diversas cores e seus respectivos valores de absortância.

É utilizada a metodologia proposta para determinar um valor aproximado de absortância em um banco de dados composto por 41 edifícios, com mais de 340 pontos de análise, localizados na região de Brasília-Brasil. Os edifícios possuem revestimento cerâmico e variam de 5 a 48 anos de construção. Para exemplificar a utilização da absortância, é proposta uma aplicação na simulação higrotérmica, que é descrita no item 2.2.

\subsection{Simulação}

São escolhidos quatro edifícios dentre as opções contidas no banco de dados e com o auxílio da metodologia adaptada de Dornelles (2007b) são determinadas as absortâncias (tabela 1) para se realizar a simulação. Todos os edifícios possuem revestimento cerâmico e, sendo assim, opta-se por realizar a simulação somente na fachada norte.

Tabela 1 - Idades e absortância de cada edifício. 


\begin{tabular}{|c|c|c|c|}
\hline EDIFÍCIO & IDADE & ABSORTÂNCIA & ORIENTAÇÃO \\
\hline 12 & 19 & 34,6 & NORTE \\
\hline 31 & 24 & 62,5 & NORTE \\
\hline 9 & 36 & 55,2 & NORTE \\
\hline 23 & 43 & 28,2 & NORTE \\
\hline
\end{tabular}

Com o auxílio do programa WUFI Pro $5.0 \AA$, é realizado uma simulação de transferência de calor em cada edifício, na orientação norte, a fim de se estudar o comportamento do revestimento com relação ao transporte térmico. Para a simulação higrotérmica são colocados no programa os dados de entrada, na qual é realizada a caracterização do sistema e das propriedades dos materiais que irão constituir cada camada, além de determinar os dados do clima onde o edifício está localizado e os coeficientes.

As propriedades dos materiais são obtidas do Relatório Interno do LEM-UnB (BAUER; NASCIMENTO; CASTRO, 2015). Os coeficientes necessários para a simulação são a resistência superficial externa (Rse) e interna (Rsi), absortância $(\alpha)$ e refletividade, onde com exceção da absortância, que é obtida pela metodologia descrita neste trabalho, o restante é estabelecido pelo próprio programa.

Os dados do clima são obtidos por meio dos arquivos climáticos TMY (Typical Meteorological Year) e da base EPW/ANTAC (RORIZ, 2012), que são dados horários de um ano climático típico, configurados para simulação computacional. Após essa etapa é realizada a simulação considerando o tempo de um ano, resultando assim nos dados de saída, que, para esse estudo, se relacionam à temperatura.

A fachada é representada durante a simulação da seguinte forma: são colocados 5 pontos de análise, sempre entre as camadas. A primeira camada é a da peça cerâmica $(0,5 \mathrm{~cm})$, seguida pelo emboço argamassado $(2 \mathrm{~cm})$, bloco cerâmico $(9 \mathrm{~cm})$ e por fim, a argamassa de revestimento interno $(2 \mathrm{~cm})$. O programa WUFI Pro $5.0{ }^{\circledR}$ gera dados relacionados ao transporte de calor que são analisados com o auxílio do programa Excel. Com relação a temperatura, analisou-se a amplitude térmica e temperatura máxima de cada mês, como é descrito com mais detalhe posteriormente.

\subsection{Temperatura máxima}

A partir dos dados de saída do programa WUFI Pro 5.0 ® é calculado a temperatura máxima mensal (Tmáx), que é a maior temperatura registrada no mês para os dados da simulação. Os dados analisados são tanto da temperatura superficial externa (temperatura da superfície do revestimento), como da temperatura ambiente (temperatura ambiente externa) para o cálculo da temperatura média anual (1).

Tméd $=\frac{\sum T_{\text {máx }} i}{12}$

Onde Tméd é a média das temperatura máximas, Tmáx i é a temperatura máxima registrada no mês i, 12 é a quantidade total de meses.

\subsection{Amplitude térmica}

A amplitude térmica (2) é a diferença entre a temperatura máxima diária pela temperatura mínima diária, na qual é registrada para cada mês a maior amplitude diária, além do cálculo da amplitude térmica média registrada para cada edifício. Os dados analisados também são os da temperatura superficial e da temperatura ambiente para o cálculo da amplitude térmica média (3). 
$\Delta T=T m a ́ x-T m i ́ n$

Onde $\Delta \mathrm{T}$ é a amplitude térmica, Tmáx é a temperatura máxima diária e Tmín é a temperatura mínima diária.

$\Delta T_{\text {méd }}=\frac{\sum \Delta T \text { máx } i}{12}$

Onde $\Delta \mathrm{T}$ méd é a média da amplitude térmica máxima, $\Delta \mathrm{T}$ máx i é a amplitude térmica máxima registrada no mês i, 12 é a quantidade total de meses.

\section{RESULTADOS}

\subsection{Tabela resumo}

A tabela resumo apresenta a aplicação da metodologia proposta, adaptada de Dornelles (2007b) para determinação de um valor aproximado de absortância, em que é aplicado o método e os valores da absortância de 41 edifícios são estipulados e tabelados com suas respectivas cores, como está descrito na tabela 2. O valor de absortância pode ser usado para simulações, possibilitando uma análise do comportamento térmico dos edifícios. Os valores de absortância determinados são distintos, variam de $28,2 \%$ a $72,9 \%$, mostrando que o banco de dados possui cores claras que absorvem pouca energia térmica e cores escuras que absorvem mais energia térmica.

Tabela 2 - Tabela Resumo. 


\begin{tabular}{|c|c|c|}
\hline EDIFÍCIO & ABSORTÂNCIA (\%) & COR \\
\hline 1 & 28,2 & BRANCO \\
\hline 2 & 28,2 & BRANCO \\
\hline 3 & 34,6 & AMARELO \\
\hline 4 & 72,9 & AMARELO \\
\hline 5 & 72,9 & AZUL \\
\hline 6 & 28,2 & BRANCO \\
\hline 7 & 72,9 & AZUL \\
\hline 8 & 28,9 & BRANCO \\
\hline 9 & 55,2 & AMARELO \\
\hline 10 & 34,6 & AMARELO \\
\hline 11 & 34,6 & AMARELO \\
\hline 12 & 34,6 & AMARELO \\
\hline 13 & 37,5 & AZUL \\
\hline 14 & 63,5 & VERMELHO \\
\hline 15 & 37,5 & AZUL \\
\hline 16 & 56,1 & AMARELO \\
\hline 17 & 56,1 & AMARELO \\
\hline 18 & 56,1 & AMARELO \\
\hline 19 & 56,1 & AMARELO \\
\hline 20 & 56,1 & AMARELO \\
\hline 21 & 56,1 & AMARELO \\
\hline 22 & 56,1 & AMARELO \\
\hline 23 & 28,2 & BRANCO \\
\hline 24 & 28,2 & BRANCO \\
\hline 25 & 37,5 & BRANCO \\
\hline 26 & 37,5 & BRANCO \\
\hline 27 & 37,5 & BRANCO \\
\hline 28 & 63,5 & VERMELHO \\
\hline 29 & 63,5 & VERMELHO \\
\hline 30 & 63,5 & VERMELHO \\
\hline 31 & 62,5 & MARROM \\
\hline 32 & 60,3 & CINZA \\
\hline 33 & 60,3 & CINZA \\
\hline 34 & 60,3 & CINZA \\
\hline 35 & 60,3 & CINZA \\
\hline 36 & 60,3 & CINZA \\
\hline 37 & 60,3 & CINZA \\
\hline 38 & 60,3 & CINZA \\
\hline 39 & 60,3 & CINZA \\
\hline 40 & 56,1 & AMARELO \\
\hline 41 & 60,3 & CINZA \\
\hline
\end{tabular}

\subsection{Temperatura máxima}

A temperatura máxima mensal está descrita na figura 1, onde se observa que em todos os meses, os valores estão em concordância com a absortância, pois quanto maior a absortância, maior a temperatura. Se obteve os maiores valores de temperatura máxima no mês de julho, dando destaque para o edifício $31\left(48,87^{\circ} \mathrm{C}\right)$, seguido pelo $9\left(46,42^{\circ} \mathrm{C}\right), 12\left(39,49^{\circ} \mathrm{C}\right)$ e $23\left(37,34^{\circ} \mathrm{C}\right)$. Já os menores valores ocorreram no mês de dezembro, seguindo a mesma ordem do mês de julho, com o edifício $31\left(35,09^{\circ} \mathrm{C}\right)$, seguido pelo $9\left(34,08^{\circ} \mathrm{C}\right), 12\left(31,48^{\circ} \mathrm{C}\right)$ e $23\left(30,73^{\circ} \mathrm{C}\right)$. Ademais, observa-se que quanto maior a absortância, maior é o valor da temperatura máxima. 


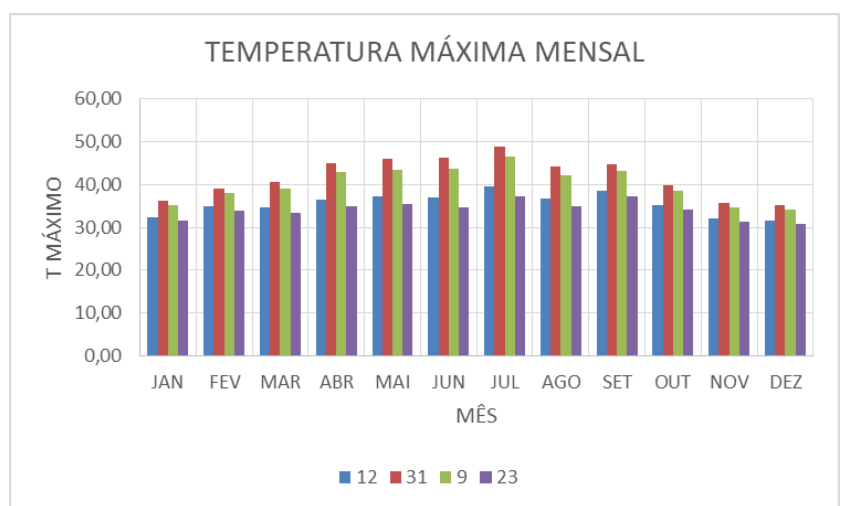

Figura 1 - Temperatura máxima mensal.

Os valores médios de temperatura máxima anual são descritos na figura 2, são calculados para a superfície da fachada de cada edifício e a temperatura ambiente, que por sua vez será igual para todos, já que estão na mesma cidade. $\mathrm{O}$ maior valor de média das temperaturas máximas é do edifício $31\left(41,77^{\circ} \mathrm{C}\right)$, seguido pelo $9\left(40,10^{\circ} \mathrm{C}\right), 12\left(35,47^{\circ} \mathrm{C}\right), 23\left(34,10^{\circ} \mathrm{C}\right)$ e a menor é a temperatura ambiente $\left(29,35^{\circ} \mathrm{C}\right)$. Nota-se que quanto menor a absortância menor é o incremento de temperatura, quando comparado com a temperatura ambiente. Já a figura 3 mostra a relação entre a absortância e a média das temperaturas máximas de cada edifício, onde observa-se uma relação praticamente linear entre os valores, revelando que existe uma relação entre absortância e temperatura máxima.

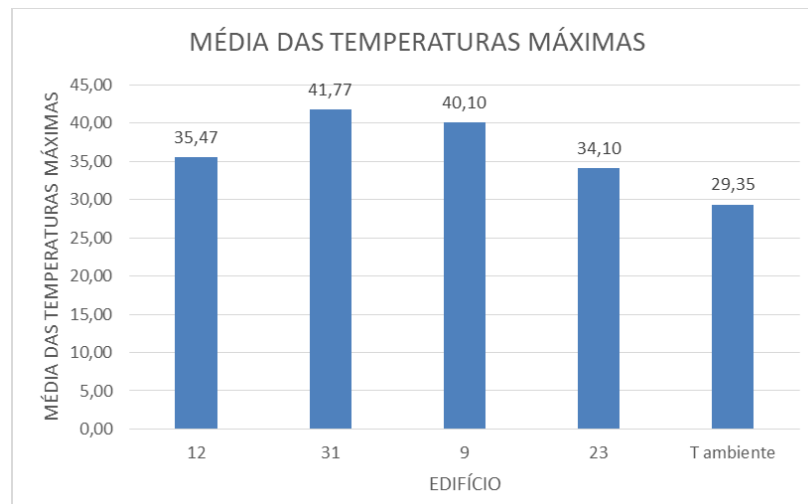

Figura 2 - Média das temperaturas máximas mensais da superfície e da temperatura ambiente.

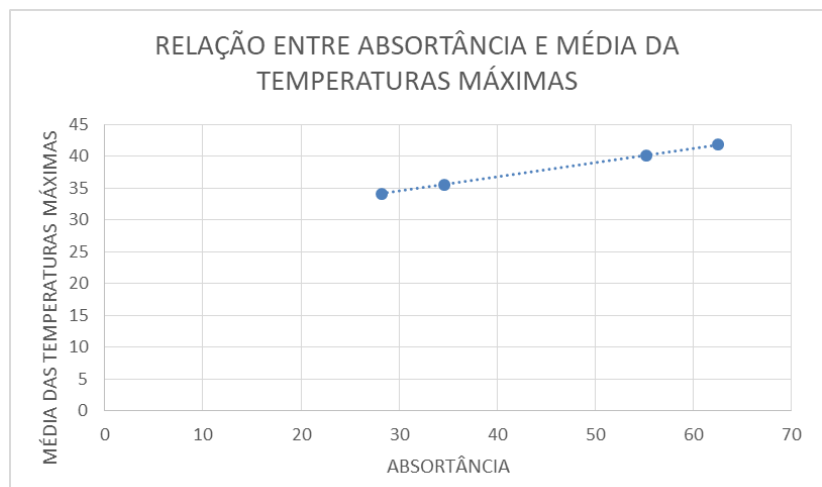

Figura 3 - Relação entre absortância e média das temperaturas máximas da superfície da fachada. 


\subsection{Amplitude térmica}

A amplitude térmica máxima mensal é apresentada na figura 4, onde os maiores valores ocorreram no mês de julho, com o edifício $31\left(31,66^{\circ} \mathrm{C}\right)$, seguido pelo $9\left(29,28^{\circ} \mathrm{C}\right), 12\left(22,55^{\circ} \mathrm{C}\right)$ e 23 $\left(20,46^{\circ} \mathrm{C}\right)$. Já os menores valores são observados no mês de dezembro, novamente seguindo a mesma ordem com o edifício $31\left(15,74^{\circ} \mathrm{C}\right)$, seguido pelo $9\left(14,69^{\circ} \mathrm{C}\right), 12\left(11,77^{\circ} \mathrm{C}\right)$ e $23\left(11,08^{\circ} \mathrm{C}\right)$. Observa-se que a amplitude térmica também tem relação com a absortância, pois quanto maior a absortância maiores são os valores de amplitude.

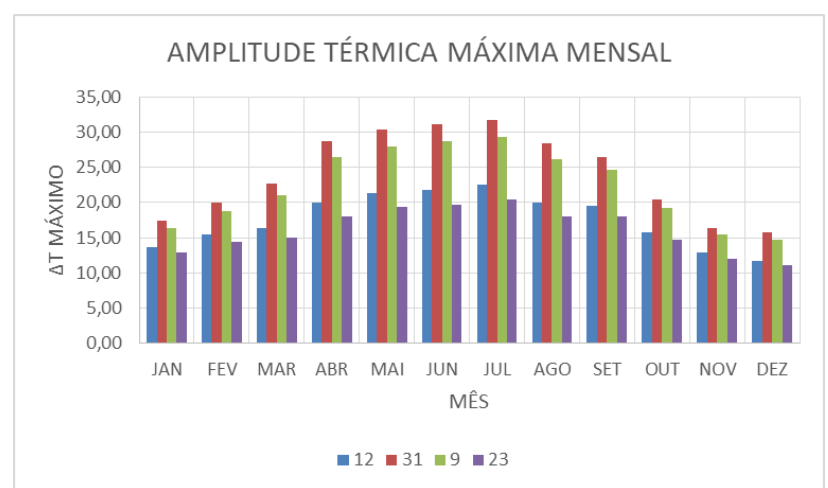

Figura 4 - Amplitude térmica máxima mensal.

A média das amplitudes térmicas máximas na superfície de cada edifício e da temperatura ambiente são apresentadas na figura 5, onde segue a mesma ordem da média das temperaturas máximas, com o edifício $31\left(24,12^{\circ} \mathrm{C}\right)$ com os maiores valores, seguido pelo $9\left(22,41^{\circ} \mathrm{C}\right), 12\left(17,61^{\circ} \mathrm{C}\right), 23$ $\left(16,15^{\circ} \mathrm{C}\right)$ e a temperatura ambiente com o menor valor $\left(12,53^{\circ} \mathrm{C}\right)$. Ademais, observa-se que quanto menor a absortância, menor é o incremento da amplitude, quando comparado com a temperatura ambiente. A relação entre a absortância e a média das amplitudes térmicas para cada edifício é apresentada figura 6 , onde observa-se uma relação praticamente linear, mostrando assim que existe uma correlação entre absortância e amplitude térmica.

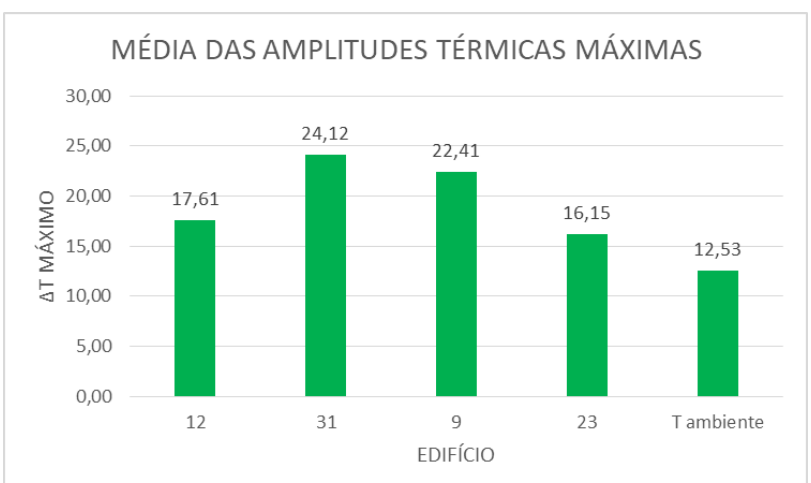

Figura 5 - Média da amplitude térmica máxima da superfície e da temperatura ambiente. 


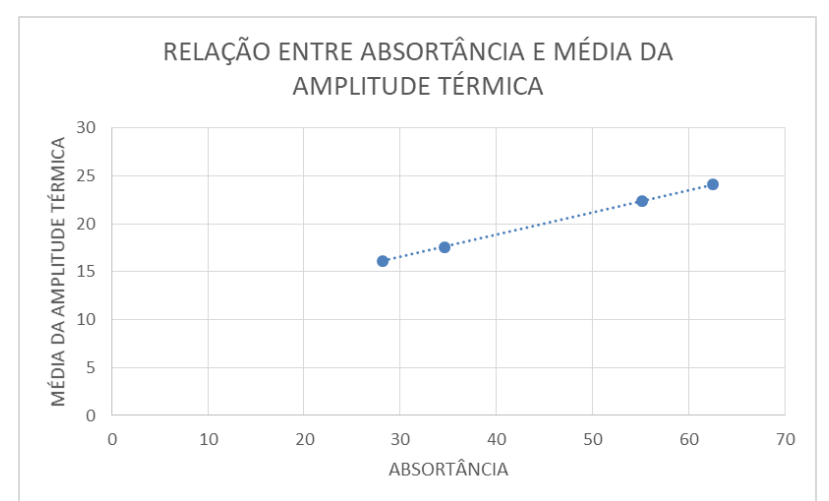

Figura 6-Relação entre absortância e média das amplitudes térmicas da superfície da fachada.

Os resultados apresentados mostram a influência da absortância em parâmetros associados à temperatura superficial das fachadas, como temperatura máxima e amplitude térmica. O que condiz com a afirmativa de que a absortância tem influência no fluxo térmico das edificações (DORNELLES; RORIZ, 2007a). Diversos autores (THOMAZ, 1989; SARAIVA, 1998; FIORITO, 2009) concordam que a fissuração e o desplacamento ocorrem principalmente por causa da variação térmica, que pode gerar variações dimensionais que são danosas ao edifício. Logo, revestimentos com elevados valores de absortância podem estar relacionados com processos mais intensos de degradação, o que impacta no desempenho e vida útil das fachadas.

\section{CONCLUSÕES}

O artigo tem como objetivo descrever uma metodologia de avaliação comparativa, adaptada de Dornelles (2007b), para determinar um valor aproximado da absortância. Com os valores obtidos por esse método, são realizadas quatro simulações no programa WUFI Pro $5.0 \AA$, analisando a amplitude térmica máxima e temperatura máxima de cada mês de quatro edifícios distintos, como forma de exemplificar uma utilização da absortância. Tendo por base o que é exposto, é possível concluir que a absortância tem influência na temperatura superficial dos edifícios e que o método adaptado de Dornelles (2007b), é uma alternativa para determinação dos valores aproximados de absortância da fachada, possibilitando assim a realização de simulações. A própria norma de desempenho ABNT NBR 15575 (2013) expõe apenas três valores, sendo um parâmetro que necessita de valores mais precisos para alcançar simulações mais próximas da realidade.

\section{REFERENCIAS}

ASSOCIAÇÃO BRASILEIRA DE NORMAS TÉCNICAS. (2005). NBR 15220-1: desempenho térmico de edificações - parte 1: definições, símbolos e unidades. Rio de Janeiro.

ASSOCIAÇÃO BRASILEIRA DE NORMAS TÉCNICAS. (2013). NBR 15575-1: Edificações habitacionais - Desempenho Parte 1: Requisitos gerais. Rio de Janeiro.

BAUER, E.; NASCIMENTO, M.L.M.; CASTRO, E.K. (2015). Parâmetros e ensaios fisicos de materiais e componentes da fachada. Relatório interno - Laboratório de Ensaio de Materiais (LEM) $-\mathrm{UnB} / \mathrm{ENC}$.

CHVATAL, K. M. S. (2014). Avaliação do Procedimento Simplificado da NBR 15575 Para Determinação do Nível de Desempenho Térmico de Habitações. Ambiente Construído, Porto Alegre, v. 14, n. 4, p. 119-134, out./dez. 
COELHO, T. da C. C.; GOMES, C. E. M.; DORNELLES, K. A. (2017). Desempenho térmico e absortância solar de telhas de fibrocimento sem amianto submetidas a diferentes processos de envelhecimento natural. Ambiente Construído, Porto Alegre, v. 17, n. 1, p. 147-161, jan./mar. 2017. ISSN 1678-8621 Associação Nacional de Tecnologia do Ambiente Construído. http://dx.doi.org/10.1590/s1678-86212017000100129.

DORNELLES, K. A.; RORIZ, M. (2007a). Influência das tintas imobiliárias sobre o desempenho térmico e energético de edificações. X Congresso Internacional de Tintas. Anais...São Paulo.

DORNELLES, K. A.; RORIZ, M. (2007b). A ILUSÃO DAS CORES NA IDENTIFICAÇÃO DA ABSORTANCIA SOLAR DE SUPERFÍCIES OPACAS. In: IX ENCAC E VII ELACAC, 2007, Ouro Preto. Anais... Ouro Preto: ANTAC.

FIORITO, A. J. S. I. (2009). Manual de Argamassa e Revestimento - Estudo e Procedimento de Execução. Editora Pini, São Paulo, SP.

NASCIMENTO, M. L. M. (2016). Aplicação da Simulação Higrotérmica na Investigação da Degradação de Fachadas de Edifícios. Dissertação de Mestrado em Estruturas e Construção Civil, Departamento de Engenharia Civil e Ambiental, Universidade de Brasília, Brasília, DF, 173p.

RORIZ, M. (2012). Correções nas Irradiâncias e Iluminâncias dos arquivos EPW da Base ANTAC. Grupo de Trabalho sobre Conforto e Eficiência Energética de Edificações. ANTAC Associação Nacional de Tecnologia do Ambiente Construído. São Carlos - SP.

RORIZ, M. (2008). Apostila da Disciplina CONFORTO E DESEMPENHO TÉRMICO DE EDIFICAÇÕES, São Carlos - SP.

SARAIVA, A. G. (1998). Contribuição ao Estudo de Tensões de Natureza Térmica em Sistema de Revestimento Cerâmico de Fachada. Dissertação de Mestrado apresentada à Faculdade de Tecnologia da Universidade de Brasília, Brasília, DF.

SILVA, M. N. B. (2014). Avaliação Quantitativa da Degradação e Vida Útil de Revestimentos de Fachada - Aplicação ao Caso de Brasília/DF. Tese de Doutorado em Estruturas e Construção Civil, Publicação E.TD-006A/14, Departamento de Engenharia Civil e Ambiental, Universidade de Brasília, Brasília, DF, 198 p.

THOMAZ, E. (1989). Trincas em Edificios: causas, prevenção e recuperação. São Paulo: PINI, EPUSP, IPT.

WUFI Pro 5.3. IBP - Fraunhofer Institute for Building Physics. Holzkirchen, Germany, 2013.

ZANONI, V.A.G. (2015). Influência dos agentes climáticos de degradação no comportamento higrotérmico de fachadas em Brasília. Tese de Doutorado em Arquitetura e Urbanismo. Programa de Pós-Graduação da Faculdade de Arquitetura e Urbanismo da Universidade de Brasília, Brasília, DF, 293 p. 